\title{
Los puntos de interés turístico: Relevancia analítica, propuesta metodológica y caso de estudio
}

\author{
Hugo Padrón-Ávila* \\ Universidad de La Laguna (España) \\ Raúl Hernández-Martín** \\ Universidad de La Laguna (España)
}

\begin{abstract}
Resumen: Los puntos de interés turístico son aquellos lugares que cuentan con una serie de recursos que motivan la atracción de visitantes hacia los mismos. El conocimiento de los puntos de interés turístico de un destino ayuda a analizar las actividades que realizan los turistas en el mismo y los patrones de movilidad llevados a cabo para ello. Los objetivos del trabajo son elaborar una serie de conceptos relacionados con los puntos de interés y crear una clasificación de dichos puntos que sea aplicable a Canarias. Además, se identifican los puntos de interés de un caso de estudio, la isla de Lanzarote. Se han empleado datos del ISTAC para saber cómo influyen las características de los visitantes en la creación de itinerarios. Los resultados alcanzados tienen interés desde la perspectiva del desarrollo de ciertas zonas, la movilidad de los turistas y la creación de productos turísticos.
\end{abstract}

Palabras clave: puntos de interés turístico, movilidad, itinerario turístico, rastreo de turistas, Canarias

Tourist points of interest: Analytical relevance, methodological proposal and study case

Abstract: Tourist interest points are places that have a set of resources which attract visitors towards them. The knowledge of the tourist attractions of a destination helps analyzing the activities carried out by the tourists and the mobility patterns carried out for it. The objectives of the paper are developing a set of concepts and definitions related to the points of interest and creating a classification of them applicable to the Canary Islands. In addition, tourist interest points of Lanzarote have been identified and classified. ISTAC data have been used to know how the characteristics of visitors influence in creating itineraries. The results obtained are interesting from the perspective of the development of certain areas, the mobility of tourists and the creation of tourist products.

Keywords: tourist points of interest, mobility, tourist itinerary, tracking tourists, Canary Islands

\section{Introducción}

Los puntos de interés turístico son aquellos lugares de un destino turístico a los que se dirigen los visitantes para poder realizar ciertas actividades o disfrutar de unos recursos determinados. Ello genera una serie de desplazamientos por parte de los visitantes dentro del destino. El conocimiento de estos desplazamientos posibilita el análisis de los movimientos que realizan los turistas dentro del destino por parte de los gestores del mismo. A pesar de ello, no se trata de un ámbito de estudio recurrente en la investigación científica del turismo, por lo que no se han elaborado estudios variados en la materia. Además, las investigaciones realizadas se han centrado en el análisis de los recursos que motivan la visita y no en los lugares a los que se dirigen los visitantes.

\footnotetext{
* Investigador en la Cátedra de Turismo CajaCanarias - Ashotel - ULL; E-mail: hpadrona@ull.es

** Profesor titular en el departamento de Economía Aplicada y Métodos Cuantitativos de la Universidad de La Laguna y director de la Cátedra de Turismo CajaCanarias-Ashotel - ULL; E-mail: rahernan@ull.es
} 
En este trabajo se han elaborado una serie de conceptos para definir términos que no habían sido establecidos previamente (Organización de las Naciones Unidas, 2010). Con ello se pretende que puedan ser utilizados como referencia en futuras investigaciones. Los conceptos creados permiten diferenciar distintos tipos de recursos y puntos de interés, estableciendo cómo han de ser analizados y sus características. En este estudio se toma la isla de Lanzarote como caso práctico a partir del que desarrollar la investigación. Por ello, se han identificado los puntos de interés de la isla y se explica la metodología llevada a cabo para su recopilación. Tras ello, se ha elaborado una taxonomía de puntos de interés turístico de Canarias que se ha basado en la realizada por McKercher (2016) y se han clasificado los puntos identificados.

La recopilación de los puntos de interés de la isla ha permitido diferenciar una serie de zonas en las que abundan los mismos. Ello posibilita el conocer dónde se concentra la actividad y permite comparar estas zonas con los microdestinos delimitados por el Instituto Canario de estadística (ISTAC). Además, se analizan las características de los visitantes de las que tiene información el ISTAC y se relacionan con sus patrones de visita de algunos puntos de interés. A pesar de que la encuesta es la herramienta utilizada actualmente por el ISTAC para la recopilación de la información, en el trabajo se explica su ineficacia para la recolección de información sobre los puntos de interés. Por ello, se proponen una serie de herramientas que, combinadas, posibilitarían la recogida de los datos deseados.

Al final del trabajo se señalan las limitaciones que presenta el estudio realizado. Además, se explica la problemática asociada a la utilización de herramientas de rastreo de los visitantes, al ser necesario el consentimiento de los visitantes analizados para poder ser empleadas. También se deja constancia de las limitaciones de las distintas técnicas estudiadas y la necesidad de combinarlas con el fin de poder recabar la información deseada. Sin embargo, se exponen algunas de las múltiples implicaciones que conllevaría la puesta en marcha de estas medidas, tanto para los agentes públicos como privados. Además de los avances que generaría en la investigación turística.

\section{Antecedentes}

El turismo es una actividad que implica el desplazamiento de personas a un destino con motivo de disfrutar de uno o varios de los recursos de los que dispone el mismo. Dichos recursos se ubican en ciertos lugares del destino turístico visitado. Dichos lugares son por ello conocidos como puntos de interés turístico. El conocimiento de los puntos de interés turístico con los que cuenta un destino es de especial importancia para la Administración Pública y las autoridades locales, pues permite conocer cómo se mueven los visitantes, cómo actúan y cómo se desenvuelven en la zona. Sabiendo esto, se pueden poner en marcha medidas que permitan redistribuir los flujos de turistas por vías diferentes con el fin de reducir la afluencia de visitantes a ciertos recursos y fomentar la actividad en otros (Smallwood, Beckley y Moore, 2012).

Los estudios de turismo necesitan de datos comparables y métodos cuantitativos para poder definir geográficamente la actividad. Los instrumentos estadísticos solo pueden medir agentes controlables, pero en el turismo pocos de estos agentes existen. Podemos medir la afluencia de visitantes a lugares de interés turístico que cuentan con algún tipo de sistema de control de las visitas, como los museos, pero el fenómeno más interesante para ser estudiado y los conflictos relacionados con la actividad, suelen tener lugar en los espacios públicos. Hay métodos para contabilizar y comparar flujos turísticos en estos espacios, donde los locales y turistas comparten un espacio determinado (Kádár, 2014). Además de las técnicas tradicionales de utilización de encuestas para conocer dónde han estado los turistas, en los últimos años también se comienzan a emplear otras medidas. Entre ellas nos encontramos con el uso de los GPS de los teléfonos móviles para saber cómo se mueven los visitantes o la puesta en marcha de mecanismos de control en las carreteras o vías de acceso a los recursos y puntos de interés turísticos (Smallwood, Beckley y Moore, 2012).

Como mecanismos de rastreo, las nuevas tecnologías digitales presentan ciertos problemas morales y éticos, lo que debe gestionarse si se pretenden emplear como instrumentos de investigación totalmente funcionales. La mayor parte de dichos problemas se relacionan con el modo en que estos dispositivos pueden ser contrarios al derecho a la intimidad de los turistas (Shoval e Isaacson, 2007). Además, las empresas de telefonía móvil tienen la capacidad de localizar y señalar la posición de los usuarios de los teléfonos, información que ellos entonces pueden emplear para bombardear a los usuarios con 
publicidad e información no solicitada sobre funciones y acontecimientos cercanos (Curry, 2000). De hecho, los sistemas legales aún no se encuentran totalmente preparados para afrontar esta realidad y la problemática asociada a la misma (Renenger, 2002), por lo que la información recopilada puede ser empleada para dichos fines. Parece que el abuso de la intimidad es el menor de los problemas en el caso de la investigación del comportamiento turístico, ya que la gente rastreada es supervisada durante un período de tiempo limitado y definido (Shoval e Isaacson, 2007). Sin embargo, esto puede dar lugar a una nueva dificultad si los turistas, una vez saben que están siendo estudiados, pudiesen cambiar su comportamiento y, en dicho caso, conocer cómo se ha modificado el mismo.

Se han llevado a cabo numerosos estudios para intentar clasificar los productos y recursos turísticos en distintas categorías, pero cada uno de ellos se ha realizado de manera independiente y con poca referencia a los estudios previos. Las diferencias en la metodología empleada para ello varían, además, en función de las características de los destinos y de los turistas. Ello ha generado clasificaciones diferentes que, en muchos casos, son muy similares y, en otros, presentan variaciones significativas (McKercher, 2016). A la hora de realizar clasificaciones en turismo se pueden emplear tipologías o taxonomías. McKercher (2016) propone la realización de una taxonomía en lugar de una tipología para clasificar los puntos de interés turísticos. La razón por la que considera que le empleo de taxonomías es mejor que el de tipologías es que las taxonomías son sistemas con base empírica que sirven para clasificar objetos utilizando características observables y medibles; mientras que las tipologías tienden a basarse en conceptos y nociones sobre un objeto ideal, por lo que podrían no ser encontradas en la realidad. En su caso, analiza las clasificaciones realizadas por diferentes autores a escala internacional y procede, a partir de las mismas, a realizar una taxonomía propia de recursos turísticos, con el fin de convertirla en el marco de referencia a utilizar en el futuro (McKercher, 2016).

En el caso de la taxonomía de McKercher (2016), los puntos de interés deben clasificarse dentro de una categoría determinada. La misma está incluida, al mismo tiempo, dentro de una categoría de orden superior y esta otra en otra categoría y así sucesivamente hasta poder diferenciar 5 categorías que engloban y definen cada punto de interés. Las categorías diferenciadas por McKercher son Motivo de Clasificación, Familia de Productos, Clase de Producto, Línea de Productos y Tipo de Producto, dentro de las cueles nos encontramos con el Objeto. El Motivo de Clasificación representa la necesidad básica que subyace a la familia de productos. La Familia de Productos incluye todas las clases de productos que pueden satisfacer una necesidad básica. La Clase de Producto representa un grupo de productos que tienen cierta coherencia funcional. La Línea de Productos incluye productos estrechamente relacionados que realizan funciones similares. El Tipo de Producto representa objetos que comparten una apariencia similar. El Objeto representa un elemento distinto o un producto específico. Por lo tanto, todas las categorías de nivel inferior comparten el tipo de producto y fijan los tipos de categorías de alto nivel.

Aunque ser capaz de clasificar los puntos de interés turístico en categorías es importante, se ha de tener en cuenta que no todos estos puntos son visitados por los turistas que se alojan en el destino. Ya se ha estudiado cómo afectan las motivaciones e intereses de los visitantes para incitar que los mismos acudan a unos u otros puntos en función de los recursos de los que disponen los mismos (Zoltan y McKercher, 2015). Fennell (1996), por ejemplo, divide a los turistas entre turistas de intereses especiales y turistas de motivaciones generales, y se encontró con que los de intereses especiales realizaron más desplazamientos a través del área del destino en la búsqueda de esos intereses. También fueron significativamente más propensos a visitar los recursos con menor afluencia de visitantes. Masiero y Zoltan (2013) se encontraron con que las personas que viajan por razones de búsqueda de la novedad cultural son más propensas a moverse ampliamente a través de un destino. Sin embargo, los que viajan para disfrutar del paisaje y la naturaleza, o para realizar una actividad física, confluyen áreas específicas, pero recorren mayores distancias durante sus viajes. Finsterwalder y Laesser (2013) definen esferas de consumo experimentales en las que los turistas contribuyen a la creación de su experiencia a través de encuentros con los proveedores de servicios especializados en las actividades que consumen, y establece los patrones de visita derivados de ello. De hecho, diversos estudios han probado que las características de los visitantes influyen en sus patrones durante el viaje (e.g. Paulino Valladepérez, L. y Prats Plangumà, L., 2015; Finsterwalder, J. y Laesser, C., 2013). El poder reconocer la importancia del papel de los patrones de consumo en la actividad turística y el movimiento de los turistas en el destino permite a los proveedores de servicios poder cubrir mejor 
las necesidades de los turistas y desarrollar una mayor variedad de productos hechos a medida para ellos (Zoltan y McKercher, 2015).

Sin embargo, estudios recientes demuestran que existen otros factores, además de dichas motivaciones, que son los que condicionan el que los turistas visiten un lugar u otro. Se ha comprobado que la ubicación del establecimiento alojativo ejerce un efecto significativo sobre los patrones de comportamiento durante el viaje, influyendo en la probabilidad de visitar ciertos núcleos y recursos turísticos, en las horas del día en que los lugares son más susceptibles de ser visitados y en la secuencia de las visitas (Shoval, McKercher, Ng, y Birenboim, 2011). Es por ello que es necesario ubicar los puntos de interés en el destino para analizar los patrones de desplazamiento de los visitantes. Si los estudios se centran simplemente en el análisis de los recursos en función de las motivaciones de los visitantes que acuden a los mismos, no se puede explicar por qué dos recursos de características similares poseen una gran variación en cuanto al número de visitantes. Mientras que el análisis y la recopilación de los puntos de interés cercanos a los establecimientos turísticos explican por qué en ciertos lugares se produce una afluencia turística mayor a la de otros (Zoltan y McKercher, 2015).

En un nivel conceptual, el trabajo de Shoval et al. (2011) destaca el impacto de la distancia en los movimientos turísticos a nivel de microdestinos. El estudio también tiene amplias implicaciones para caracterizar los movimientos turísticos y la planificación y desarrollo urbano de los destinos. Lew y McKercher (2004) han sugerido que los flujos urbanos turísticos claramente tienen una tendencia a extenderse desigualmente, tanto espacial como temporalmente. Ello también explica que en los sitios que son más populares y tienen accesos a diferentes rutas sean en los que más a menudo confluyan un número excesivo de personas, mientras que otros lugares son poco frecuentados. Todo ello refleja el empleo poco eficiente de los recursos económicos y sociales, pudiendo llegar a ocasionar, en última instancia, un desarrollo insostenible del destino.

Los estudios de Shoval et al. (2011) concluyen que la actividad se ve espacialmente concentrada alrededor del hotel existen lugares que a los que los turistas probable o improbablemente visitarán según dónde se alojen, la ubicación del establecimiento afecta al volumen de visitantes de los recursos turísticos cercanos (salvo al de los recursos más populares de la zona), y los patrones de visita difieren según el lugar de estancia. La comprensión de las implicaciones de la posición de hotel sobre el movimiento físico y temporal de los turistas puede ayudar al desarrollo de esquemas de dirección turísticos y nuevos nodos turísticos para ayudar a gestionar el número de visitantes de un modo más racional.

Una vez identificados los recursos turísticos y geolocalizados en distintos puntos de interés es posible, mediante el uso de diferentes mecanismos, conocer cómo se desplazan los visitantes y establecer el orden en el que visitan los diferentes lugares. Con ello se podrían llegar a elaborar itinerarios turísticos en función de, como se ha nombrado anteriormente, la ubicación del establecimiento alojativo y los patrones de consumo del turista. Ello podría tener un efecto trascendental en la actividad, ampliando las actuales fronteras existentes en los estudios del turismo, así como ayudando a mejorar la toma de decisiones en materia de política turística, además de la planificación y la gestión de la misma (Shoval e Isaacson, 2007).

A pesar de la relevancia e implicaciones que puede generar la categorización de los puntos de interés y el control de los visitantes a los mismos, esta materia no ha sido abordada en profundidad en la investigación turística. Nos encontramos con que son muchos los autores que han definido qué es un recurso, pero cada uno de ellos ha creado sus propias definiciones en función de las necesidades de la investigación en curso y las características del destino analizado. La propia Organización Mundial del Turismo (OMT) ha creado definiciones para poder establecer qué es el turismo, un destino turístico o una actividad turística. Sin embargo, no ha podido crear definiciones que sirvan como marco de referencia para definir qué se considera un atractivo turístico o un recurso turístico, a pesar de ser términos ampliamente utilizados en la literatura científica (Organización de las Naciones Unidas, 2010). Por ello, tampoco se han podido establecer qué parámetros o indicadores mínimos han de tener lugar para considerar a un destino o recurso determinado como turístico, debido a que esto se ve fuertemente condicionado por consideraciones subjetivas y por las características específicas de la zona estudiada (e.g. Organización Mundial del Turismo, 2007; Xiuli y Zhong, 2005).

Del mismo modo, al no haber podido establecer qué es un recurso o un destino, y qué no lo es, tampoco se ha definido qué es un punto de interés turístico. Wall (1997) realiza una clasificación de los mismos y los diferencia entre puntos, líneas y áreas turísticas; que considera que pueden tratarse del mismo atractivo, pero considerado a diferente escala. Así, por ejemplo, a escala nacional, las áreas 
turísticas serían aquellas tales como complejos costeros o parques nacionales. Por otro lado, considera que una simple área de destino puede ser vista como una combinación de puntos, líneas y áreas; configurándose como un conglomerado de nodos y conexiones. Sin embargo, él mismo asegura que incluso un único atractivo turístico, como un parque temático o un museo, puede ser también visto desde esta perspectiva. Por ello, la conceptualización provee cierta flexibilidad con respecto a la escala. A pesar de ser un avance en la investigación en la materia, resultan conceptos demasiado ambiguos, al poder considerar un mismo espacio como un punto o un área en función de la investigación que se realice. Por ello, se han de definir en cada estudio qué se considera un punto de interés y el nivel de profundidad en el que va a analizarse.

\section{Objetivos}

Para la realización del trabajo se ha estudiado la literatura científica relacionada con la clasificación y conceptualización de los recursos turísticos. Con ello se pretenden crear una serie de definiciones que sirvan para explicar una serie de conceptos, entre ellos el de punto de interés turístico. Además, se pretende crear una taxonomía de dichos puntos de interés, partiendo de la clasificación elaborada por McKercher (2016), que pueda ser aplicable a Canarias. Para justificar la relevancia del trabajo, se pretenden establecer cuáles son los puntos de interés de un caso de estudio, la isla de Lanzarote. Tras ello, se pretenden conocer las diferencias entre las características de los visitantes que acuden a cada uno de estos lugares y saber, además, cómo influyen ciertos factores (sociodemográficos, ubicación del alojamiento en el destino y motivaciones) en sus patrones de visita durante el viaje. Por último, se explicarán cuáles son las actuales limitaciones existentes en la recogida de información de los turistas y se propondrán medidas de mejora con las que podría recopilarse más datos e información.

\section{Metodología}

Para la realización del trabajo, se han revisado los conceptos elaborados y empleados por diferentes autores e investigadores, además de los aceptados por la OMT (Organización de las Naciones Unidas, 2010). A partir de ello, se han podido estudiar sus diferencias y limitaciones con el objetivo de elaborar una serie de definiciones que resulten válidas para este estudio. Del mismo modo, se ha utilizado la taxonomía de recursos turísticos elaborada por McKercher (2016) para elaborar una clasificación propia de puntos de interés que pueda ser aplicable a Canarias. Tras la búsqueda de puntos de interés en Lanzarote, se han clasificado los mismos según la taxonomía elaborada. Para la realización de la búsqueda se han empleado diferentes medios. Algunos de los medios principales de referencia han sido portales web gubernamentales, como el portal oficial de turismo de la isla; así como fuentes estadísticas públicas, como el directorio de establecimientos turísticos del ISTAC o los Centros de Cultura, Arte y Turismo del Centro de Datos de Lanzarote.

$\mathrm{Al}$ tratarse de fuentes que recogen puntos de interés únicamente desde la perspectiva de la oferta, se han analizado diferentes webs para establecer los mismos desde un enfoque de demanda. Por ello, se ha realizado una búsqueda en Airbnb para recopilar las viviendas vacacionales disponibles en la isla. Del mismo modo, se ha utilizado TripAdvisor como medio para establecer qué bares, restaurantes, pubs, discotecas, etc. son turísticos; debido a que, desde un enfoque de oferta, todas estas empresas lo serían, incluso aquellas en las que no consumieran los turistas. También cabe destacar el empleo de Instasights para conocer cuáles son los lugares más fotografiados de la isla, pues permite establecer como puntos de interés ciertos lugares que no están recogidos en el resto de webs, como los paisajes.

Para intentar conocer las características de los visitantes que acuden a cada punto, se han empleado los datos del ISTAC y el Centro de Datos de Lanzarote relativos a la afluencia de visitantes a estos lugares. Además, se ha empleado información del ISTAC para conocer qué factores incentivan en mayor medida la visita de los puntos de interés de los que se disponen datos. La información del ISTAC ha sido obtenida a partir de las respuestas de los turistas a los que se les realizó la Encuesta de Gasto Turístico durante 2015. Para obtener la información se han filtrado estos datos y se han realizado tablas de sumarización por medio del programa estadístico SAS. 


\section{Marco conceptual desarrollado}

Como ya se ha explicado, no existen definiciones universales que definan qué es un recurso o un punto de interés turístico (Organización de las Naciones Unidas, 2010). Existen algunas definiciones que han sido elaboradas por diversos autores en función de las necesidades específicas de la investigación en la que estuvieran involucrados. Por ello, en este trabajo se intenta crear un marco conceptual que sirva como referencia a la hora de estudiar los puntos de interés de un destino y el movimiento realizado por los turistas entre estos lugares para realizar diversas actividades. Para elaborar estos conceptos se han revisado otras definiciones ya elaboradas y se han estudiado sus limitaciones. Además, se ha intentado que las definiciones pudiesen ser aplicables a otros destinos y ámbitos de estudio. Se han ilustrado los conceptos con ejemplos que ayudan a su comprensión y facilitan su diferenciación.

Podríamos definir un recurso turístico desde dos perspectivas, la de demanda y la de oferta. Desde el punto de vista de la demanda, se trata de todo elemento, de cualquier naturaleza, que posee la capacidad de, o bien atraer visitantes a un destino para disfrutar del mismo, o de mejorar la experiencia de los visitantes en dicho destino. Desde el punto de vista de la oferta, se trata de todo elemento que puede ser empleado para la generación o producción de actividades turísticas, o que puede emplearse para la gestión de las empresas turísticas o del propio destino. Por ello, un recurso turístico desde el punto de vista de la demanda podría ser un elemento tangible, como un museo o un sendero; pero también un elemento intangible, como la amabilidad de la población local o un evento de carácter religioso. Desde la perspectiva de la oferta, se consideran recursos turísticos también otros elementos como la formación y experiencia del personal o la cultura empresarial. Además, para una empresa son recursos turísticos tan solo aquellos elementos con los que elabora los servicios que ofrece, no siéndolo la propia actividad ofertada, mientras que la misma sí es un recurso turístico desde un enfoque de demanda. Si consideramos dentro del enfoque de oferta al destino turístico, las actividades ofrecidas por las empresas serían recursos turísticos para el destino.

Cabe hacer mención de aquellos recursos que únicamente pueden disfrutarse en ciertos momentos o períodos del año. Estos recursos modifican el interés de los visitantes por acudir a ciertos lugares en períodos específicos, por lo que generan puntos de interés de manera temporal. Además, para los destinos, generan la necesidad de establecer ciertas medidas puntuales que garanticen la correcta gestión de los visitantes que acuden a dichos lugares. Se trata de un tipo de recurso turístico que tiene lugar en un momento dado y que posee una baja o nula frecuencia de repetición. Dentro de este tipo de recursos podemos encontrar una diversa serie de eventos que pueden poseer una frecuencia preestablecida y otros que son difíciles de predecir o controlar. Como ejemplos podemos citar el Ironman de Lanzarote (con una frecuencia definida) o las nevadas en el Teide (un suceso imprevisto). Además, nos encontramos con que ciertos eventos, pudiendo o no tener una frecuencia determinada, no se producen de manera constante, sino que tienen lugar en momentos distantes en el tiempo. Como ejemplos podemos citar la Bajada de la Virgen de Las Nieves en La Palma (se trata de un evento con una frecuencia preestablecida, pero que se produce una vez cada cinco años) o la erupción de un volcán (es un suceso natural que no puede controlarse y que no muestra una constancia temporal). Todos ellos serían recursos turísticos temporales.

Sin embargo, podemos diferenciar entre recursos turísticos anuales, ocasionales y puntuales. Los anuales son aquellos que se producen, como mínimo, una vez al año y pueden tratarse tanto de eventos organizados, como aleatorios. Los ocasionales son aquellos eventos organizados que tienen lugar con una frecuencia mayor a un año, pero inferior a una década. Por último, los puntuales son todos aquellos sucesos preestablecidos que tienen lugar una vez transcurridos diez o más años, o que no se tratan de eventos organizados y tienen lugar con una frecuencia superior al año. Aquellos sucesos que tienen lugar y que no se espera que vuelvan a repetirse, serían considerados también recursos turísticos puntuales. Como ejemplo de recurso anual nos encontraríamos las celebraciones del Carnaval. La Bajada de La Virgen de Los Reyes de El Hierro sería un recurso ocasional. Por último, los eclipses solares o el concierto de un cantante determinado, serían recursos turísticos puntuales. Cabe mencionar que un recurso turístico puntual puede convertirse en anual u ocasional si se le asigna una frecuencia que se ajuste a los parámetros establecidos y vuelve a repetirse.

A partir de los recursos, y sus características, se crean actividades turísticas, pudiendo definirlas como todo uso que se le da a uno o varios recursos turísticos. Es por ello que las actividades ponen en valor los recursos que emplean, haciendo posible que sean disfrutados por el visitante. La realización 
de actividades puede ser ofrecida por una empresa o Administración Pública, o ser realizada por los visitantes sin necesidad de contratarla. Así, la realización de una excursión por una ciudad puede ser contratada o diseñada por el propio visitante; tratándose en ambos casos de una actividad turística. La posibilidad de realizar algún tipo de actividad turística en un lugar es lo que hace que el mismo suscite interés a los visitantes y, por tanto, lo convierte en un punto de interés turístico.

Un punto de interés turístico puede definirse como un lugar concreto, dentro de un destino turístico, en el que se ubican uno o varios recursos turísticos y se realizan actividades turísticas a partir de los mismos. El recurso que atrae a los visitantes puede tratarse, en ocasiones, del propio punto de interés. Por ejemplo, la visita al interior de una iglesia puede ser de interés para los visitantes, ello hace que la misma sea un punto de interés y, al mismo tiempo, el propio lugar es el recurso turístico que resulta interesante para los mismos. En otros casos, como en el de los museos, el interés no radica en el lugar en sí, sino en algunos de los elementos que contiene; en este caso, las obras de arte.

También existen puntos de interés turístico temporales, que están relacionados con los recursos turísticos temporales. Al celebrarse algún tipo de evento, ciertas zonas generan una atracción de visitantes mayor a la habitual, convirtiéndose en puntos de interés temporales. En principio podría parecer que los recursos turísticos temporales y los puntos de interés temporales son lo mismo. Sin embargo, existen lugares que atraen visitantes de manera constante y la celebración de eventos únicamente fomenta dicha afluencia en los mismos. En estos casos, el punto de interés no es temporal, ya que los turistas lo disfrutan todo el año. Sin embargo, el evento en sí se trata de un recurso turístico de carácter temporal. Además, el recurso temporal es siempre un evento o suceso, mientras que el punto de interés temporal es el lugar en el que se desarrolla el mismo (un pueblo, sendero, edificio, etc.). Hablamos de puntos de interés turístico temporales cuando únicamente se produce una afluencia significativa de visitantes a los mismos durante un período temporal determinado.

En todo destino encontramos lugares a los que acuden los turistas de manera significativa y que, sin embargo, no generan un interés en los visitantes. A estos lugares acuden los mismos debido a que resultan indispensables para poder disfrutar del destino. Entre estos sitios podemos destacar las infraestructuras necesarias para el transporte y movilidad de los visitantes, los establecimientos alojativos y de restauración o ciertas oficinas gubernamentales. Algunos ejemplos serían las paradas de transporte público, los aeropuertos y muelles, hoteles y apartamentos, bares y restaurantes, paradas de taxi, oficinas de información turística, puestos de control de viajeros en las fronteras de los países, oficinas de alquiler de vehículos, aparcamientos, etc. Estos lugares son los puntos de concentración turística. Se diferencian de los puntos de interés al servir como medio para poder disfrutar de estos últimos y por no generar una afluencia de visitantes por sí mismos.

En ocasiones es complicado delimitar un punto de interés, llegando a encontrar zonas amplias que generan la atracción de visitantes. En estos sitios no es posible establecer qué lugares de los mismos son los que generan la afluencia de visitantes, dificultando la labor de establecer puntos de interés dentro de los mismos. Además, incluso identificándose cuáles son los lugares en los que se detienen los visitantes, no es posible confirmar qué puntos son los que han generado realmente la atracción. Ello se debe a que la existencia del espacio en su conjunto es el responsable de motivar la llegada de visitantes al mismo. Por ello, se distinguen los espacios de interés turístico. Son zonas amplias, que podrían considerarse estar formadas por varios puntos de interés, pero en las que la cercanía y existencia de todos ellos es la que explica el interés suscitado por dicho espacio.

Una vez se han identificado todos los puntos y espacios de interés de un destino, puede procederse a señalizarlos en un mapa. Ello ayuda a diferenciar visualmente dónde se concentran estos lugares, identificando así unas zonas en las que abundan los mismos y otras que presentan un bajo o nulo número de ellos. Con ello nos encontramos con que existen áreas turísticas, siendo las zonas en las que existen conglomeraciones conformadas por distintos puntos y/o espacios de interés que motivan a los visitantes a acudir a las mismas para disfrutar de estos lugares. No han de confundirse con los microdestinos, que son pequeñas unidades geográficas que depende en gran medida del turismo y comprende una amplia gama de instalaciones turísticas (Hernández-Martín, R. et al., 2016), por lo que se han establecido desde una perspectiva de oferta. Las áreas de interés se han señalado partiendo de un enfoque de demanda, al identificar los lugares que resultan atractivos para los visitantes. En muchos casos, los mismos pueden coincidir, ya que los establecimientos tienden a ubicarse cerca de una serie de recursos que sean adecuados para atraer a los demandantes de los mismos. Sin embargo, no siempre es así; como en el caso de las áreas naturales protegidas a las que acuden los visitantes 
para practicar senderismo, sin poder alojarse en ellas porque la construcción de infraestructuras está prohibida.

Otro concepto a destacar es el del itinerario turístico. Se trata del modo en que los visitantes enlazan puntos de interés, espacios de interés y puntos de concentración, durante un día de estancia. Estos itinerarios son diferentes para cada visitante. Sin embargo, existen herramientas capaces de recabar información relativa al orden en el que se visitan los puntos de interés, según el punto de partida del visitante y el medio de transporte empleado. Con ello se pueden generar modelos de itinerarios en función de las características de los mismos. Estos modelos pueden emplearse tanto para la mejora de la gestión pública de la actividad, como para la creación de nuevos productos. Los itinerarios pueden desarrollarse tanto dentro de una única área turística, como a través de varias de ellas, si se visitan diferentes puntos de interés distantes entre sí.

$\mathrm{Al}$ igual que existen puntos de interés temporales, también puede darse el caso de que un evento genere un itinerario turístico temporal. Se tratan de aquellas rutas que realizan los visitantes debido a un evento o suceso que posee una baja frecuencia de repetición. Se diferencian de los puntos de interés en que, para ser considerados como temporales, no es necesario que los lugares que atraviese la ruta no reciban visitantes el resto del año. Es decir, si un evento es capaz de incentivar a los turistas a desplazarse entre diferentes lugares, aun cuando se traten de puntos altamente visitados, estos turistas realizarán un itinerario temporal. La razón para considerarlo como tal es que el evento cambia los patrones de movilidad de los visitantes, incentivándolos a desplazarse de una manera determinada. Se debe señalar que no todos los recursos temporales crean itinerarios turísticos temporales, sino que solo lo hacen aquellos eventos que implican un desplazamiento por sí mismos. Un claro ejemplo de estos itinerarios son los eventos deportivos, tales como maratones o travesías de montaña (a pie, bicicleta, caballo, etc.), y determinadas fiestas religiosas, como ciertas procesiones que recorren largos trayectos.

Un último concepto asociado al de itinerario turístico es el de las vías de conexión. Se tratan de aquellos tramos del itinerario turístico que son empleados para conectar y visitar dos puntos de interés determinados. Ejemplos de vías de conexión son las carreteras o las calles. No suelen generar interés en los visitantes por sí mismas, aunque en ocasiones son las causantes del mismo, como ocurre con ciertos itinerarios turísticos temporales. Es importante conocer cuáles son las vías de conexión principales empleadas por los visitantes. Pueden explicar por qué ciertos puntos de interés son más visitados que otros (dada su cercanía con respecto a otros puntos) y también pueden ser la razón que desincentive a los visitantes a acudir a los mismos (mal estado de las carreteras, lejanía, etc.).

\section{Propuesta de clasificación de puntos y espacios de interés turístico}

A partir de la taxonomía elaborada por McKercher (2016) y de la búsqueda de los puntos de interés de la isla de Lanzarote, se ha elaborado una clasificación de puntos de interés aplicable a Canarias. A pesar de haber sido pensada para ser utilizada en el archipiélago, es posible tomarla como referencia para la elaboración de clasificaciones a nivel internacional. La clasificación elaborada es una taxonomía en la que se le asigna una categoría a cada punto de interés, la cual pertenece a su vez a otra categoría que también se encuentra dentro de otra. Así, se diferencian cinco categorías que engloban y definen las características de cada punto de interés.

Se ha establecido un único Motivo de Clasificación que define el objetivo de la clasificación. Tras la misma nos encontramos con siete Familias de Productos que engloban de manera genérica los puntos de interés clasificados. Luego, se han identificado 24 Clases de Productos, asignados a las distintas Familias de Productos, que definen el lugar en mayor profundidad. Dentro de las mismas, se reparten 80 Líneas de productos que ya especifican qué punto de interés pretende clasificarse. Por último, se han establecido 197 Tipos de Producto que especifican alguna característica relativa a las Líneas de Producto en las que se engloban. Hay que señalar que no todas las Líneas de Producto cuentan con subcategorías, pues no se ha considerado relevante ahondar aún más en sus características. Dentro de cada Tipo de Producto (o Línea de Producto en caso de no haberse subdividido) encontramos el Objeto, que sería nombre de cada uno de los puntos de interés clasificados. La taxonomía de puntos y espacios de interés turístico que se ha elaborado puede verse a continuación (Tabla 1). 
Tabla 1. Clasificación de puntos y espacios de interés turístico de Canarias

\begin{tabular}{|c|c|c|c|c|}
\hline $\begin{array}{l}\text { Motivo de } \\
\text { Clasificación }\end{array}$ & $\begin{array}{l}\text { Familia de } \\
\text { Producto }\end{array}$ & $\begin{array}{l}\text { Clase de } \\
\text { Producto } \\
\end{array}$ & Línea de Productos & Tipo de Producto \\
\hline \multirow[t]{36}{*}{ Puntos de interés } & \multirow[t]{12}{*}{ Restauración } & \multirow[t]{3}{*}{ Bebidas } & Bodega & \\
\hline & & & Licorería & \\
\hline & & & No alcohol & \\
\hline & & \multirow[t]{9}{*}{ Comida } & \multirow[t]{5}{*}{ Restaurante } & Estándar \\
\hline & & & & Étnico \\
\hline & & & & Canario \\
\hline & & & & Pescado \\
\hline & & & & Otros \\
\hline & & & \multirow[t]{3}{*}{ Bar } & Estándar \\
\hline & & & & Tapas \\
\hline & & & & Tasca \\
\hline & & & \multicolumn{2}{|l|}{ Guachinche } \\
\hline & \multirow[t]{22}{*}{ Alojamiento } & \multirow[t]{14}{*}{ Hotelero } & \multirow[t]{6}{*}{ Hotel } & 1 estrella \\
\hline & & & & 2 estrellas \\
\hline & & & & 3 estrellas \\
\hline & & & & 4 estrellas \\
\hline & & & & 5 estrellas \\
\hline & & & & Gran lujo \\
\hline & & & \multirow[t]{6}{*}{ Hotel Urbano } & 1 estrella \\
\hline & & & & 2 estrellas \\
\hline & & & & 3 estrellas \\
\hline & & & & 4 estrellas \\
\hline & & & & 5 estrellas \\
\hline & & & & Gran lujo \\
\hline & & & \multicolumn{2}{|l|}{ Hotel Rural } \\
\hline & & & \multicolumn{2}{|l|}{ Hotel Emblemático } \\
\hline & & \multirow[t]{8}{*}{ Extrahotelero } & \multirow[t]{3}{*}{ Apartamento } & 3 estrellas \\
\hline & & & & 4 estrellas \\
\hline & & & & 5 estrellas \\
\hline & & & Casa Rural & \\
\hline & & & Casa Emblemática & \\
\hline & & & Vivienda vacacional & \\
\hline & & & Zona de acampada & \\
\hline & & & Otro & \\
\hline & \multirow[t]{2}{*}{ Transporte } & \multirow[t]{2}{*}{ Aéreo } & Aeropuerto & \\
\hline & & & Helipuerto & \\
\hline
\end{tabular}




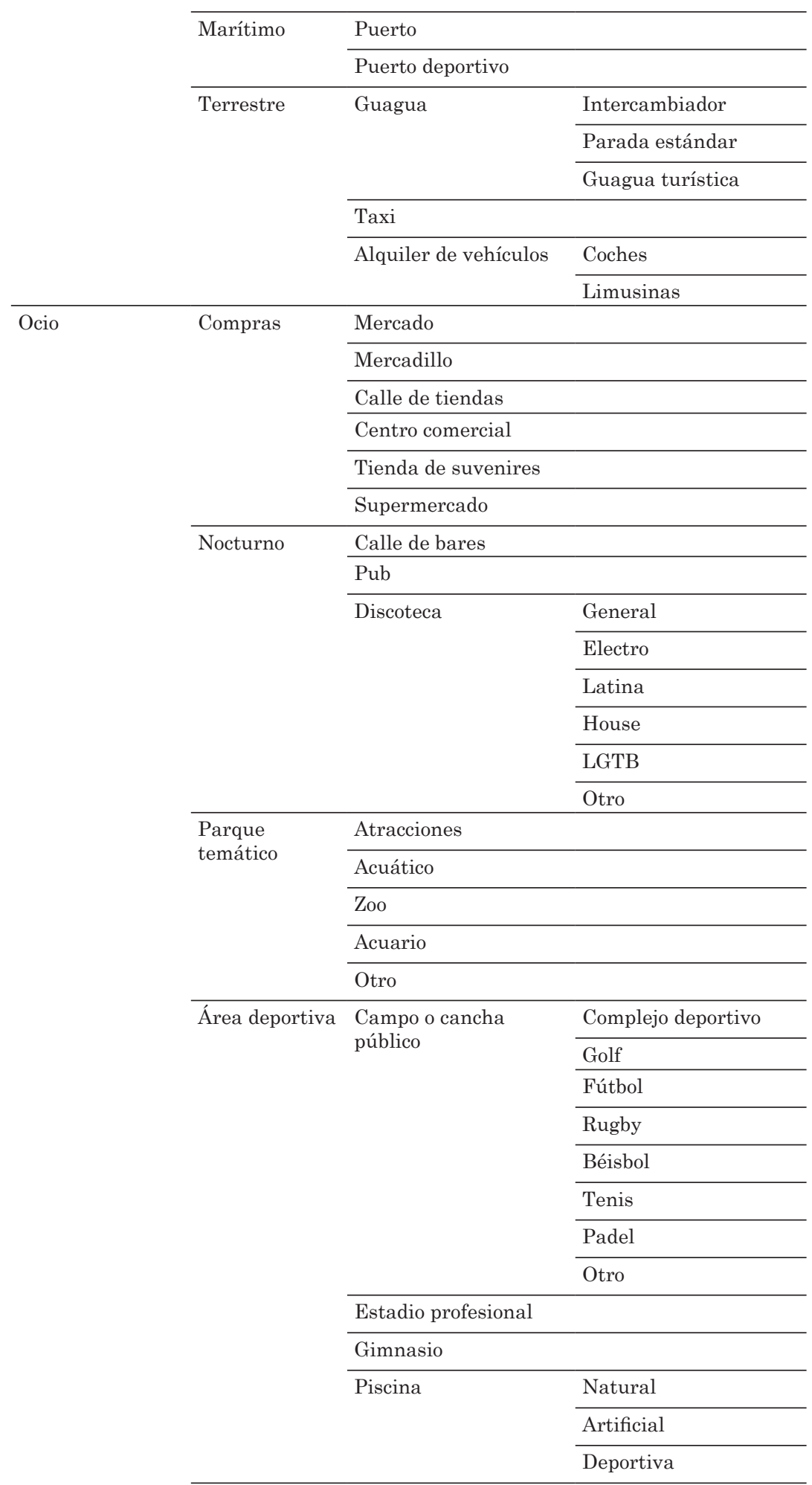




\begin{tabular}{|c|c|c|c|}
\hline & \multirow{2}{*}{$\begin{array}{l}\text { Juego y } \\
\text { apuestas }\end{array}$} & \multicolumn{2}{|l|}{ Casino } \\
\hline & & \multicolumn{2}{|l|}{ Casa de apuestas } \\
\hline & \multirow[t]{4}{*}{ MICE } & \multicolumn{2}{|l|}{ Palacio de congresos } \\
\hline & & \multicolumn{2}{|l|}{ Sala de conferencias } \\
\hline & & \multicolumn{2}{|l|}{ Sala de eventos } \\
\hline & & \multicolumn{2}{|l|}{ Otro } \\
\hline & \multirow[t]{13}{*}{ Salud } & \multirow[t]{4}{*}{ Bienestar } & SPA \\
\hline & & & Sauna \\
\hline & & & Masaje \\
\hline & & & Otro \\
\hline & & \multirow[t]{9}{*}{ Centro médico } & Cirugía plástica \\
\hline & & & Dermatología \\
\hline & & & Dental \\
\hline & & & Óptica \\
\hline & & & Rejuvenecimiento \\
\hline & & & Reasignación sexual \\
\hline & & & Chequeo \\
\hline & & & Hospital \\
\hline & & & Centro de salud \\
\hline \multirow[t]{21}{*}{ Cultura } & \multirow[t]{11}{*}{ Religión } & \multirow[t]{5}{*}{ Templo cristiano } & Catedral \\
\hline & & & Iglesia \\
\hline & & & Ermita \\
\hline & & & Basílica \\
\hline & & & Santuario \\
\hline & & \multirow[t]{2}{*}{ Residencia religiosa } & Convento \\
\hline & & & Monasterio \\
\hline & & \multicolumn{2}{|l|}{ Otro } \\
\hline & & \multirow[t]{3}{*}{ No cristiano } & Mezquita \\
\hline & & & Sinagoga \\
\hline & & & Otro \\
\hline & \multirow[t]{10}{*}{ Tradición } & \multirow[t]{10}{*}{ Rural } & Pueblo \\
\hline & & & Pueblo costero \\
\hline & & & Casa tradicional \\
\hline & & & Campo de cultivo \\
\hline & & & Zona de pastoreo \\
\hline & & & Era \\
\hline & & & Lagar \\
\hline & & & Lavadero \\
\hline & & & Acueducto \\
\hline & & & Cantera \\
\hline
\end{tabular}




\begin{tabular}{|c|c|c|}
\hline & & \\
\hline & & Pozo \\
\hline & & Galería \\
\hline & & Otro \\
\hline & \multirow[t]{6}{*}{ Aborigen } & Grabado \\
\hline & & Necrópolis \\
\hline & & Edificación \\
\hline & & Residencia \\
\hline & & Lugar de reunión \\
\hline & & Otro \\
\hline \multirow[t]{17}{*}{$\begin{array}{l}\text { Centro de } \\
\text { visitas }\end{array}$} & \multirow[t]{8}{*}{ Museo } & $\begin{array}{l}\text { Centro de } \\
\text { interpretación }\end{array}$ \\
\hline & & Sala de exposiciones \\
\hline & & General \\
\hline & & Arte \\
\hline & & Naturaleza \\
\hline & & Historia \\
\hline & & Cultura aborigen \\
\hline & & Personaje histórico \\
\hline & \multirow[t]{5}{*}{ Representación } & Teatro \\
\hline & & Anfiteatro \\
\hline & & Auditorio \\
\hline & & Cine \\
\hline & & Centro cultural \\
\hline & \multirow[t]{4}{*}{ Ciencia } & Astronomía \\
\hline & & Vulcanología \\
\hline & & Conservación animal \\
\hline & & Otro \\
\hline \multirow[t]{12}{*}{ Urbano } & \multirow[t]{9}{*}{ Construcción exterior } & Plaza \\
\hline & & Parque \\
\hline & & Jardín \\
\hline & & Fuente \\
\hline & & Monumento \\
\hline & & Calle \\
\hline & & Avenida marítima \\
\hline & & Faro \\
\hline & & Otro \\
\hline & \multirow[t]{3}{*}{ Edificación histórica } & Palacio \\
\hline & & Castillo \\
\hline & & Vivienda tradicional \\
\hline
\end{tabular}




\begin{tabular}{|c|c|c|c|}
\hline & & & \multirow{3}{*}{$\begin{array}{l}\text { Edificio administrativo } \\
\text { Hospital }\end{array}$} \\
\hline & & & \\
\hline & & & \\
\hline & & & Escuela \\
\hline & & & Otro \\
\hline \multirow[t]{33}{*}{ Naturaleza } & \multirow[t]{9}{*}{ Acuático } & \multirow[t]{4}{*}{ Marino } & Fondo oceánico \\
\hline & & & Zona de navegación \\
\hline & & & Cetáceos \\
\hline & & & Otro \\
\hline & & \multirow[t]{5}{*}{ Agua dulce } & Lago \\
\hline & & & Laguna \\
\hline & & & Acuífero \\
\hline & & & Fuente natural \\
\hline & & & Otro \\
\hline & \multirow[t]{7}{*}{ Costa } & \multirow[t]{5}{*}{ Zona de baño } & Playa de arena \\
\hline & & & Piscina natural \\
\hline & & & Callados \\
\hline & & & Artificial \\
\hline & & & Otro \\
\hline & & \multicolumn{2}{|l|}{ Acantilado } \\
\hline & & \multicolumn{2}{|l|}{ Otro } \\
\hline & \multirow[t]{17}{*}{ Interior } & \multirow[t]{5}{*}{ Vulcanismo } & Volcán \\
\hline & & & Malpaís \\
\hline & & & Tubo volcánico \\
\hline & & & Cráter \\
\hline & & & Otro \\
\hline & & \multirow[t]{6}{*}{ Zona de montaña } & Montaña \\
\hline & & & Valle \\
\hline & & & Barranco \\
\hline & & & Cueva \\
\hline & & & Mirador \\
\hline & & & Otro \\
\hline & & \multirow[t]{6}{*}{ Bosque } & Matorral costero \\
\hline & & & Laurisilva \\
\hline & & & Pinar \\
\hline & & & Sabinar \\
\hline & & & Alta montaña \\
\hline & & & Otro \\
\hline \multirow[t]{2}{*}{ Temporal } & \multirow[t]{2}{*}{ Anual } & \multirow[t]{2}{*}{ Cultural } & Artístico \\
\hline & & & Musical \\
\hline
\end{tabular}




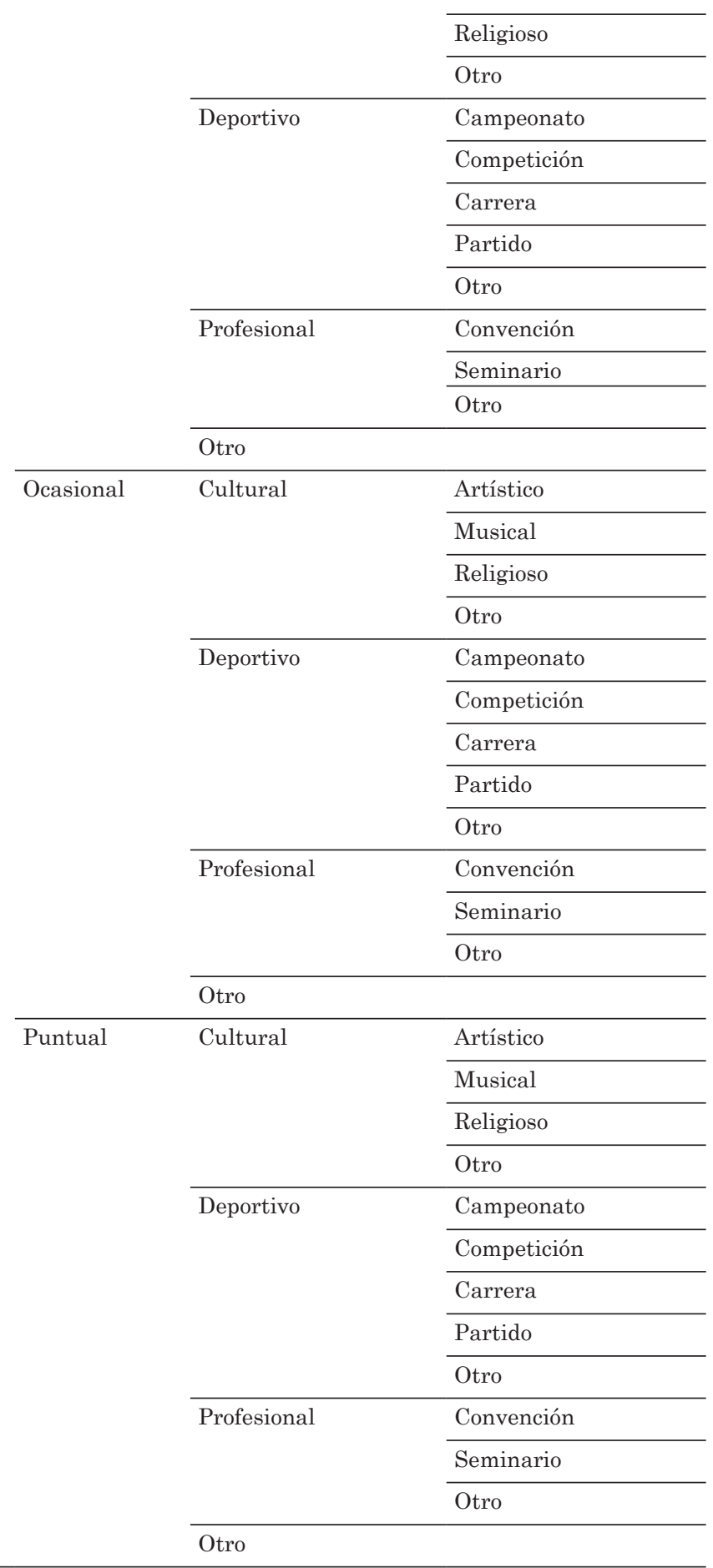

Fuente: Elaboración propia 


\section{El caso de Lanzarote}

Los puntos de interés de la isla de Lanzarote (más de 2500 puntos identificados) han sido clasificados en la taxonomía elaborada. En el presente trabajo no se ha realizado una búsqueda de puntos de interés temporales debido a que la misma solo sería de utilidad si se realizase con anterioridad a que tenga lugar el evento. Al tomar como referencia los eventos celebrados antes de 2016, la inclusión de estos puntos de interés no aportaría mejoras a la gestión de la actividad turística.

Los puntos de interés se han recogido, en algunos casos, con el nombre oficial del lugar y, en otros, con el nombre que la ha dado el propietario o alguna clase de organismo. Esto se debe a que existen ciertos puntos de interés que poseen una denominación oficial fácilmente identificable y aceptada por la Administración Pública, como es el caso de las calles, hoteles, plazas, iglesias o playas. Sin embargo, existen lugares que no cuentan con un nombre oficial que haya sido aceptado oficialmente, por lo que se le ha asignado el nombre otorgado por un tercero responsable de haber transformado el lugar en un punto de interés. En este último caso destacan las viviendas vacacionales, a las que se les ha puesto el nombre exacto con el que son vendidas en Airbnb. También es el caso de las paradas de guagua, que tienen el nombre que les ha asignado la compañía a cargo de prestar el servicio de transporte.

En el Mapa 1 pueden verse todos los puntos de interés ubicados en un único mapa. Los denominados como Ocio, Cultura y Naturaleza se ubican en la capa superior del mapa elaborado, seguidos de los de Transporte, tras ellos los de Alojamiento y, en la capa inferior, los de Restauración. Gracias a la elaboración de estos mapas se han podido establecer las áreas turísticas de la isla, que pueden verse en el Mapa 2. Una vez delimitadas, se han comparado las mismas con los microdestinos, considerándose como tales a las entidades turísticas del ISTAC. Por ello, en el Mapa 3 puede verse la ubicación de los tres microdestinos.

\section{Imagen 1. Puntos de interés turístico de Lanzarote}

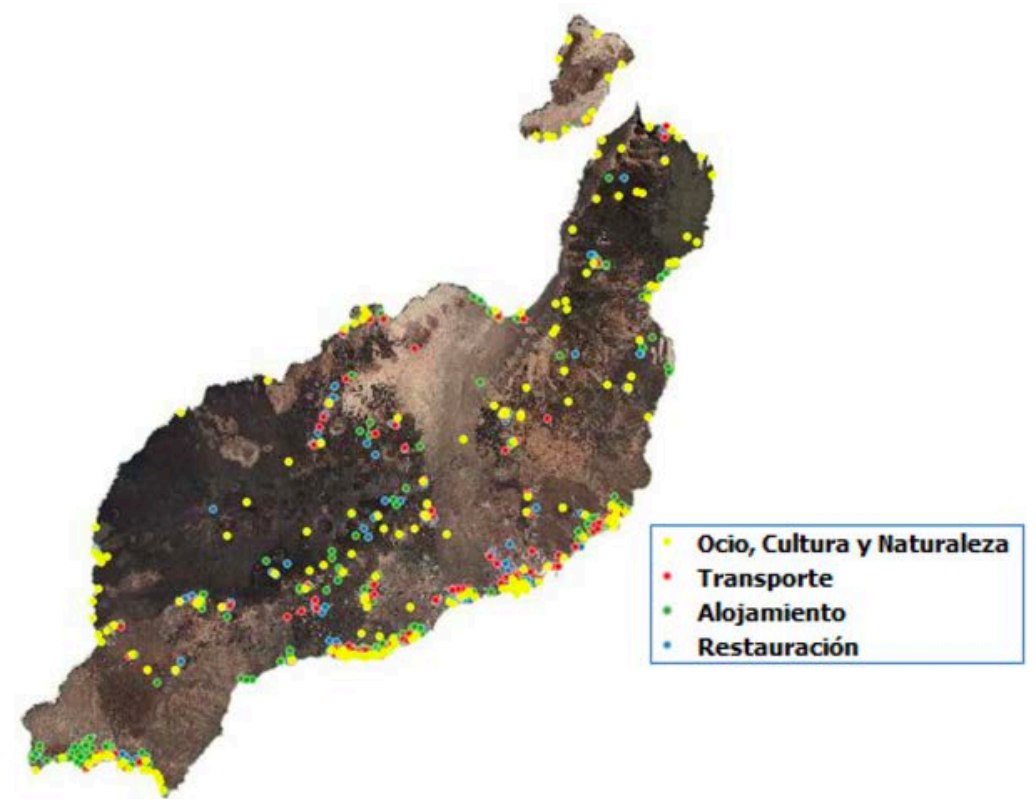

Fuente: Elaboración propia 


\section{Imagen 2. Áreas turísticas identificadas en Lanzarote}

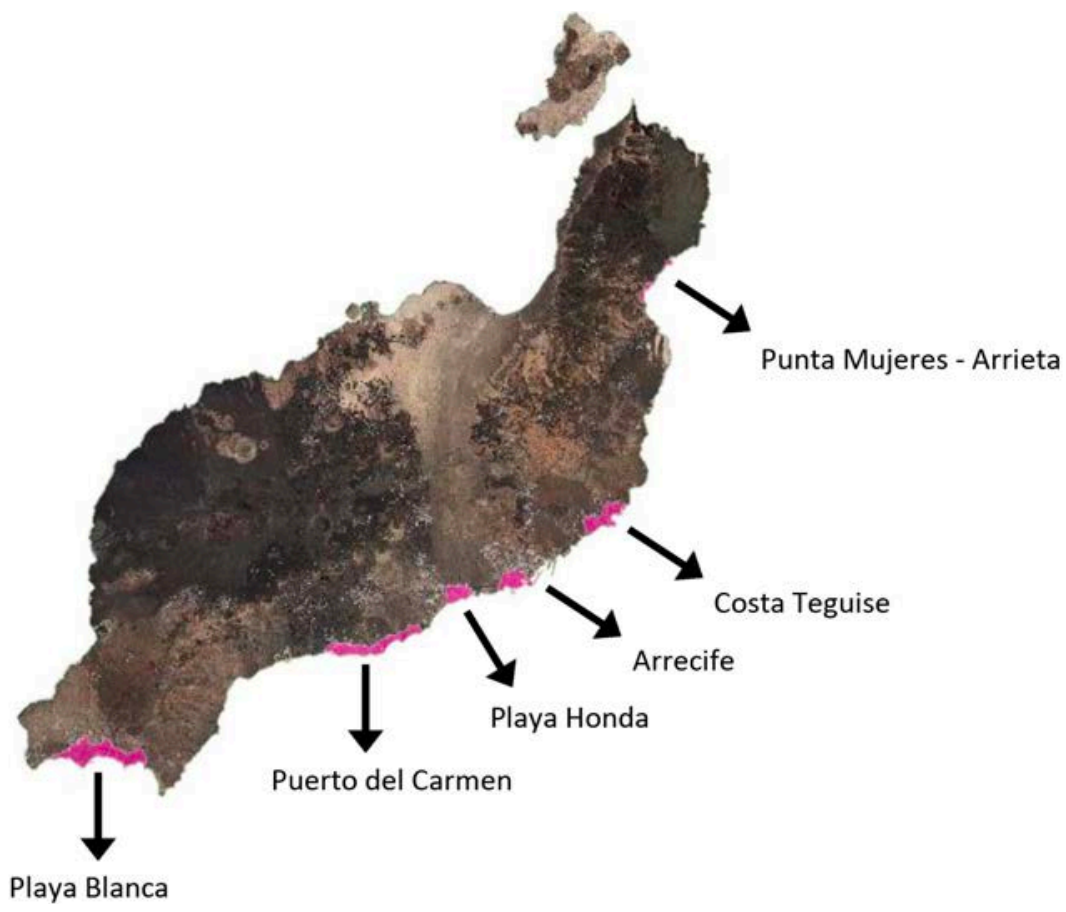

Fuente: Elaboración propia

Imagen 3. Microdestinos de Lanzarote según el ISTAC

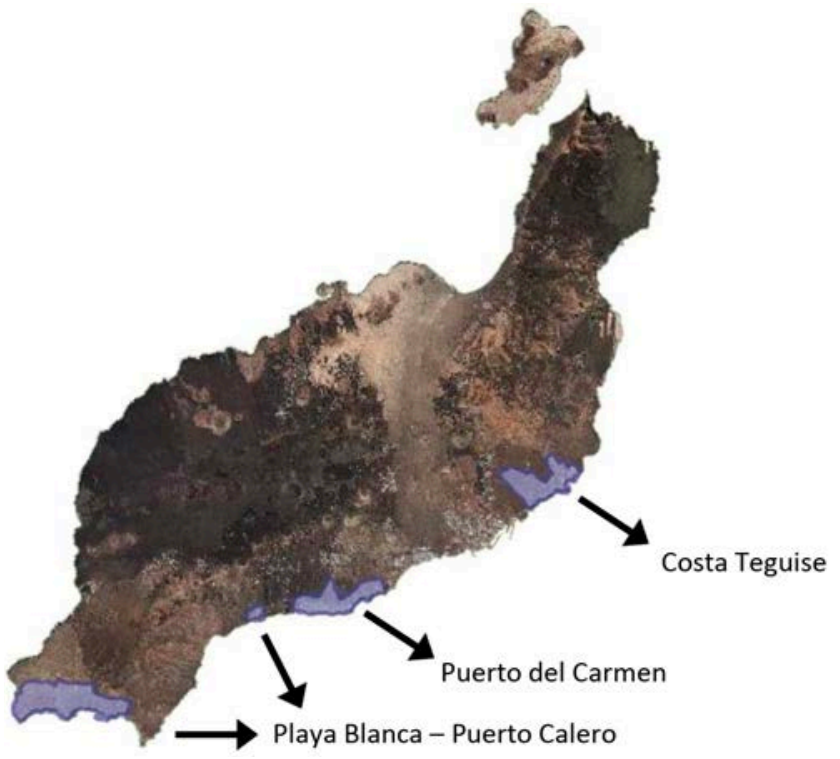

Fuente: Elaboración propia a través de imágenes de www.idecanarias.es 
Como puede observarse en las imágenes, las principales áreas turísticas identificadas (tanto en tamaño como en número de puntos que contienen) se corresponden con los microdestinos delimitados por el ISTAC. Sin embargo, también pueden apreciarse ciertas diferencias entre los mismos. En primer lugar, se han identificado un mayor número de áreas turísticas (6 en total) que de microdestinos (existen 3 al considerar Playa Blanca y Puerto Calero como una única entidad). Además, no se ha considerado a Puerto Calero como un área turística relevante ni se ha unido a ninguna de las áreas establecidas, debido a que se encuentra geográficamente alejada de las mismas. En su lugar, se ha considerado Playa Honda, Arrecife y Punta Mujeres-Arrieta como áreas turísticas, dada la cantidad de puntos de interés que existen en las mismas. La comparación entre microdestinos y puntos de interés muestra que, desde una perspectiva de demanda (áreas turísticas), el espacio delimitado es inferior, al solo tener en cuenta aquellas zonas en las que exista una alta concentración de puntos de interés de diversa índole. Sin embargo, desde una perspectiva de oferta (microdestinos) este espacio es mayor al agrupar todos los establecimientos turísticos ubicados en un mismo núcleo urbano.

\section{Factores determinantes de la visita a puntos de interés}

En el presente trabajo se han tomado como referencia la nacionalidad del turista encuestado, los aspectos por los que eligió Canarias como destino turístico y la ubicación del establecimiento alojativo en el que ha pernoctado. Todos estos datos han sido cedidos por el ISTAC y se han relacionado con la información relativa a la visita de centros turísticos recopilada a través de la Encuesta de Gasto Turístico. Todo ello ha sido procesado con el programa estadístico SAS. Un primer hecho que debía probarse es la relevancia de la ubicación del alojamiento turístico como factor que influye en la toma de decisiones relativa a la visita de puntos de interés turístico en Canarias. Este hecho ya había sido estudiado por Shoval (2011) en otros destinos, pero debía verificarse que en las islas este factor también cobraba importancia. A continuación se expone el gráfico 1, en el que se muestra el porcentaje de turistas alojados en los diferentes municipios de Lanzarote que han visitado algún punto de interés de los que el ISTAC recaba información.

\section{Gráfico 1. Afluencia porcentual de visitantes a puntos de interés turístico de Lanzarote según su municipio de estancia (2015)}

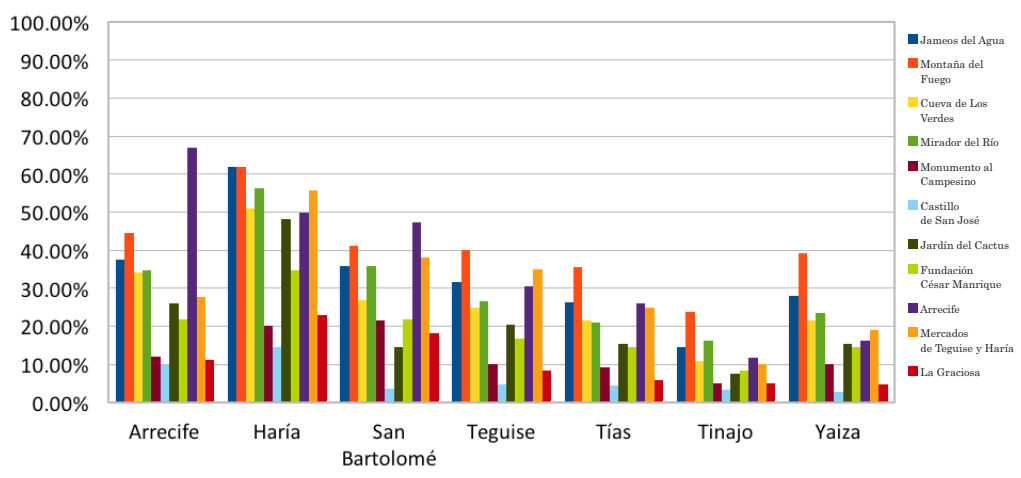

Fuente: Elaboración propia a través de datos cedidos por el ISTAC y procesados con SAS

A primera vista puede apreciarse que, efectivamente, existen diferencias relativas a los lugares visitados por los turistas en función de la ubicación del establecimiento alojativo. Los alojados en Haría parecen ser los más propensos, en general, a visitar los lugares de interés de la isla. Tan solo son superados por lo alojados en Arrecife en la visita de la propia ciudad de Arrecife y por los alojados en San Bartolomé en la entrada en el Museo al Campesino. Además, puede verse como los alojados en Tinajo son los menos propensos a visitar puntos de interés. En algunos casos parece influir la cercanía del punto de interés al establecimiento turístico (la visita de la ciudad de Arrecife), pero, en otros casos, parece que este factor no cobra tanta importancia (la visita a La Graciosa no es practicada con mayor 
frecuencia por los alojados en Arrecife, Haría y San Bartolomé que por los alojados en Teguise, a pesar de ubicarse en este municipio).

El hecho de que existan municipios en los que se alojen visitantes más propensos a visitar puntos de interés genera dos hipótesis. Por un lado, es posible que los turistas elijan la ubicación del alojamiento debido a que les gusta el lugar en el que se encuentra el mismo y los que se alojan en ciertos lugares son más propensos, por sus motivaciones, a visitar diferentes puntos de interés del destino. Por otro, puede que se elija el alojamiento debido a que se encuentra relativamente cercano a los lugares que pretenden visitar y que sea la cercanía de los mismos lo que los motiva a elegirlo. De cualquier modo, parece que las motivaciones tienen un papel fundamental a la hora de incentivar a los turistas a visitar puntos de interés. Las motivaciones de los turistas que están relacionadas con los puntos de interés analizados, y según el municipio de estancia de los mismos, puede verse en el gráfico 2.

\section{Gráfico 2. Porcentaje de visitantes que han seleccionado alguno de los siguientes aspectos de elección de Lanzarote como destino turístico según municipios de estancia (2015)}

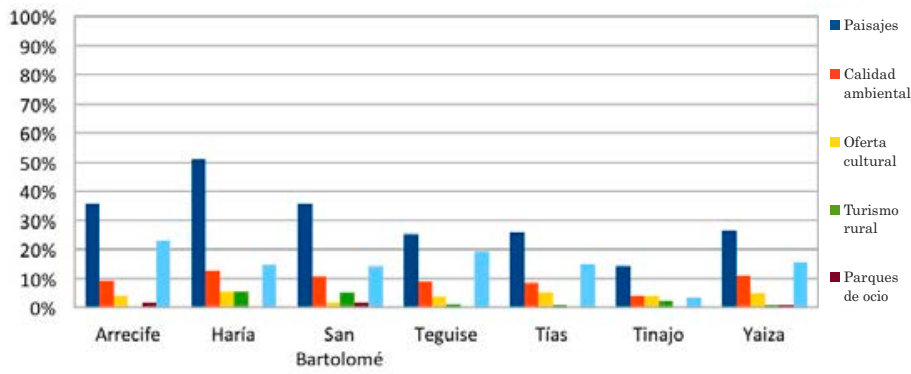

Fuente: Elaboración propia a través de datos cedidos por el ISTAC y procesados con SAS

Al comparar los dos gráficos anteriores, se aprecia que las motivaciones no son el único factor que influye en los visitantes para motivarlos a visitar un lugar determinado. Por ejemplo, se aprecia que, en Haría, ninguno de los turistas alojados en el municipio ha señalado la visita a parques de ocio como una motivación de relevancia y del mismo modo se observa que no son los más motivados por conocer nuevos lugares. A pesar de ello, según se ve en el gráfico 1, son los que tienden a visitar en mayor medida los Jameos del Agua, el Jardín del Cactus o la Fundación César Manrique. De ello también se deduce que los visitantes de ciertos lugares, a pesar de haber señalado que se sienten motivados por ciertas actividades, no las han realizado. Al saber esto, se han analizado las motivaciones de los visitantes según el punto de interés visitado en la isla de Lanzarote, lo que puede verse en el gráfico 3.

\section{Gráfico 3. Porcentaje de turistas que han señalado uno de los siguientes aspectos de elección según la visita de los puntos de interés analizados (2015)}

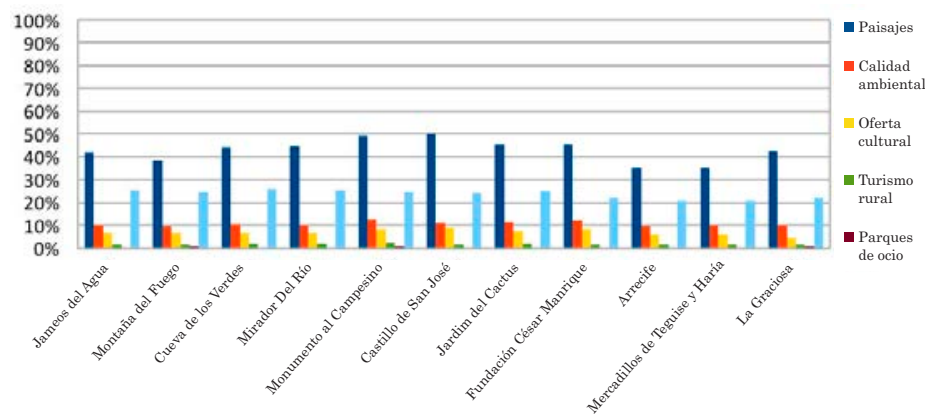

Fuente: Elaboración propia a través de datos cedidos por el ISTAC y procesados con SAS 
En este último gráfico puede verse que los turistas que visitan la Montaña del Fuego son algunos de los menos interesados por el paisaje canario, mientras que los más interesados en el mismo son los que visitan el Castillo de San José y el Monumento al Campesino. Esto podría probar que las motivaciones del visitante no influyen de manera significativa en sus patrones de visita. Sin embargo, en otros casos sí que se demuestra que las motivaciones influyen en los mismos. Por ejemplo, se aprecia que los interesados en la oferta cultural tienden a visitar en mayor medida lugares como el Castillo de San José, la Fundación César Manrique y el Monumento al Campesino. Todo este análisis prueba que la ubicación del establecimiento alojativo juega también un papel muy importante en la toma de decisiones relativa a la visita de puntos de interés turístico en Canarias. Así, existen ciertos lugares que deben la afluencia de visitantes a las motivaciones de los turistas y, otros, en los que es necesario analizar otros factores, tales como la ubicación del alojamiento turístico.

Una vez probado este hecho, se plantea la necesidad de conocer en qué medida afectan otras características de los visitantes a sus patrones de visita. Por ello, se ha analizado la influencia de ciertos rasgos socioculturales en dichos patrones. Para ello, se han cruzado los datos relativos a las visitas realizadas por los turistas con los relativos a su nacionalidad. El gráfico 4 muestra los resultados obtenidos. Cabe señalar que existen una amplia variedad de rasgos culturales que podrían haberse tenido en cuenta (edad, sexo, profesión, etc.), pero se ha escogido la nacionalidad al considerarla una característica que influye significativamente en los patrones de consumo. Además, la comparación de otros rasgos hubiese supuesto un aumento considerable de la extensión del estudio.

\section{Gráfico 4. Tendencia de afluencia de visitantes a puntos de interés según navcionalidad (2015)}

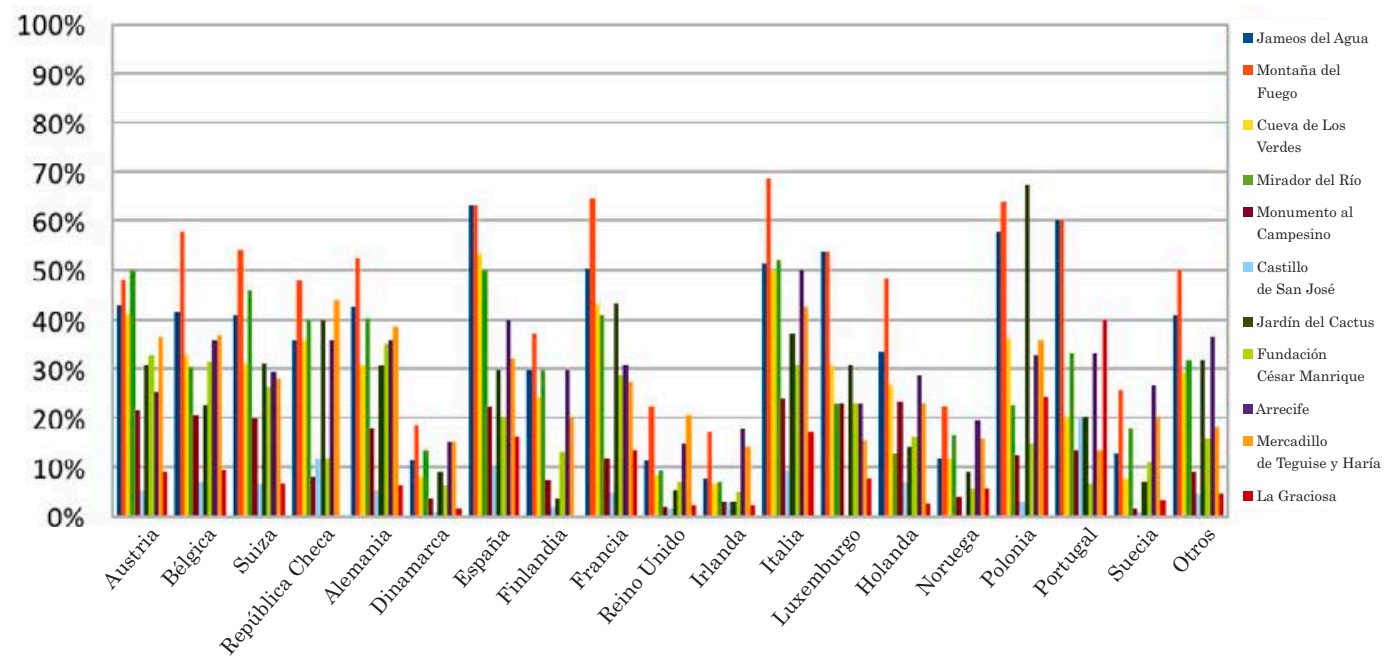

Fuente: Elaboración propia a través de datos cedidos por el ISTAC y procesados con SAS

Se aprecia que existen ciertas diferencias relativas a la visita de puntos de interés en función de la nacionalidad del visitante. Se aprecia que los daneses, británicos e irlandeses son los que muestran una tendencia menor a visitar los principales atractivos turísticos de la isla. Ello podría deberse a que prefieren disfrutar del clima canario y, para ello, permanecen en sus respectivos alojamientos turísticos y en las playas (cuya visita no es recogida por el ISTAC). Por otro lado, puede verse que los españoles, franceses e italianos son los más propensos a visitar los puntos de interés de la isla. El gráfico muestra que efectivamente la nacionalidad es un factor a considerar, debido a que existen ciertas nacionalidades más propensas que otras a visitar puntos de interés. Sin embargo, cabe destacar que no se aprecian diferencias notables relativas a la preferencia de determinados puntos de interés según la nacionalidad del visitante. Es decir, los españoles tienden a visitar en mayor medida todos los puntos de interés 
analizados, al igual que los británicos visitan en menor medida todos ellos. Sin embargo, coinciden los lugares más visitados por cada nacionalidad.

Por ello, podemos afirmar que no existen preferencias destacables entre nacionalidades en lo relativo a la visita de unos recursos o lugares determinados, pero sí en su tendencia a querer viajar dentro del destino. Sin embargo, al analizar los patrones de visita en función del municipio de estancia, sí que se han podido reconocer diferencias notables. Además, se ha probado que, al igual que ocurre con las nacionalidades, los alojados en determinados municipios visitan en mayor medida diferentes puntos de interés de la isla. La importancia de conocer estos hechos radica en la información que puede obtenerse al cruzar determinados datos. Por ejemplo, el conocer la nacionalidad del visitante permite saber su predisposición a visitar diferentes lugares de la isla y, de saberse también dónde va a alojarse, se pueden estimar los lugares que es más probable que visite.

\section{Conclusiones, implicaciones y discusión}

En este trabajo se han elaborado una serie de conceptos para subsanar algunas de las lagunas en la investigación turística. Por ello, se han definido términos como recurso turístico, puntos de interés turístico o itinerario turístico; que pueden ser empleados como referencia en investigaciones futuras. Con el objetivo de que la investigación pueda ser de utilidad en Canarias, se ha elaborado una taxonomía de puntos de interés aplicable a Canarias. Tal como refleja McKercher (2016), estas clasificaciones están fuertemente influenciadas por las características del destino analizado y de los recursos que posea. Por ello, esta taxonomía no puede ser exportable a otros destinos, al estar fuertemente marcada por elementos propios de la cultura y naturaleza canaria. Sin embargo, sí que puede ser tomada como referencia. Además, se ha utilizada la isla de Lanzarote como caso práctico para la identificación y clasificación de los puntos de interés de la misma. Tras ello, se han señalado los puntos de interés identificados en un mapa, con lo que se ha podido analizar de manera visual y sencilla dónde se ubican los mismos. Ello ha permitido establecer una serie de áreas turísticas que han sido comparadas con los microdestinos recopilados por el ISTAC.

La utilización de datos del ISTAC ha permitido conocer cuáles son las características y motivaciones de los turistas que influyen en mayor medida en la visita de puntos de interés. Tras el análisis se ha podido concluir que la nacionalidad del turista y la ubicación del establecimiento alojativo son factores relevantes a la hora de poder estimar qué lugares se visitarán. Así, se ha comprobado que las personas de ciertas nacionalidades (como españoles, italianos o franceses) se muestran más propensas a visitar los puntos de interés canarios. Sin embargo, existen otras nacionalidades (como británicos o irlandeses) que muestran una tendencia muy inferior a visitar estos lugares. Además, la ubicación del establecimiento alojativo influye a la hora de motivar a los turistas a visitar unos puntos de interés u otros. De ello se concluye que conocer la nacionalidad del visitante permite estimar su propensión a visitar puntos de interés del destino y, de conocerse también dónde se alojará, se puede saber qué lugares es más probable que visite. Sin embargo, parece que las motivaciones no ejercen un papel tan significativo en este aspecto.

El conocimiento de los puntos de interés e itinerarios realizados genera una serie de beneficios para la gestión turística a escala local. A pesar de ello, existe una fuerte limitación para llevar a cabo acciones encaminadas a estos fines debido a la dificultad que representa la obtención de información en este ámbito. La Encuesta de Gasto Turístico del ISTAC no es capaz de recoger todos los puntos de interés que conforman un destino. Es por todo ello que la recopilación de la información ha de llevarse a cabo mediante técnicas diferentes a las convencionales.

Para los gestores de los destinos turísticos, permite identificar cuáles son las áreas turísticas del destino y cómo llegan los visitantes a las mismas. Sabiendo esto, se pueden poner en marcha medidas que tengan la finalidad de incrementar o reducir la afluencia de dichos visitantes a un área determinada. De igual modo, permite conocer qué impacto supondría para el destino el aumento de la oferta alojativa en una zona determinada y cómo influiría en la visita de ciertos puntos de interés. Además, ayuda a estimar qué lugares son dependientes de otros, es decir, qué puntos de interés son visitados debido a su cercanía con respecto a otro punto de interés.

Para las empresas, puede servir para crear nuevos productos turísticos o mejorar la gestión de las actividades desarrolladas. Si un establecimiento alojativo conoce a qué lugares suelen ir sus clientes al alojarse en el mismo, puede recopilar un mayor número de folletos o mapas de dichas zonas con el objetivo de ofrecerlos y mejorar su estancia. El conocimiento de los itinerarios realizados 
y vías de conexión utilizadas por los visitantes puede ser usado por las empresas para saber en qué lugares deben promocionarse para que el mensaje sea captado por un público concreto. Además, si las empresas oferentes de actividades turísticas tienen conocimiento de cómo los visitantes enlazan los servicios que cada una de ellas ofrece, pueden aliarse con el fin de que su unión mejore la experiencia de sus clientes o reduzca costes. Para agencias de viajes y turoperadores suponen un modo de conocer lugares de interés para los turistas que resultan difíciles de identificar y que podrían incluir en sus paquetes.

En el presente trabajo se han estudiado los puntos de interés de la isla de Lanzarote. Con ello se han podido establecer cuáles son las áreas turísticas de la isla y los lugares en los que existe una mayor abundancia de establecimientos alojativos. Sin embargo, la aplicación práctica de la investigación se ve limitada dado que no se han podido rastrear los movimientos de los turistas para identificar itinerarios turísticos en la isla, al no haber información relativa al orden de visita de los puntos recopilados. Además, la utilización de otros métodos hubiese desvelado, seguramente, puntos de interés turístico adicionales. El descubrimiento de otros puntos de interés podría haber derivado en la modificación de la taxonomía elaborada. Del mismo modo, el estudio de dichos puntos en otras islas hubiese hecho necesaria la actualización de la clasificación para crear nuevas categorías que estuvieran en concordancia con los nuevos puntos descubiertos. A pesar de ello, el trabajo sirve para poder continuar la investigación en este ámbito y expandirla a toda Canarias e, incluso, ser empleada como marco de referencia en la investigación turística de otros destinos. También muestra qué características de los visitantes influyen en sus patrones de visita, lo que puede servir a los gestores de la actividad como herramienta con la que promocionar ciertos puntos de interés en los segmentos interesados en los mismos.

\section{Bibliografia}

Curry, M.

2000, The Power to Be Silent: Testimony, Identity, and the Place of Place. Historical Geography, vol. 28, pág. $13-24$.

Fennell, D.

1996. A tourist space-time budget in the Shetland Islands. Annals of Tourism Research, vol. $23, \mathrm{n}^{\circ} 4$, pág. 811- 829 .

Finsterwalder, J. y Laesser, C.

2013. Segmenting outbound tourists based on their activities: Toward experiential consumption spheres in tourism services? Tourism Review, vol. 68, nº 3, pág. 2.

Hernández-Martín, R., Simancas-Cruz, M. R., González-Yanes, J. A., Rodríguez-Rodríguez, Y., García-Cruz, J. I., \& González-Mora, Y. M.

2016. Identifying micro-destinations and providing statistical information: a pilot study in the Canary Islands. Current Issues in Tourism, vol. 19, nº 8, pág. 771-790.

Kádár, B.

2014. Measuring tourist activities in cities using geotagged photography. Tourism Geographies, vol. $16, n^{\circ} 1$, pág. $88-104$.

Lew, A. A. y McKercher, B.

2004. Travel geometry: Macro and micro scales considerations. Trabajo presentado en el encuentro antes del congreso de la Comisión de la Unión Geográfica Internacional sobre Turismo, Ocio y Cambio Global, del 13 al 15 de agosto. Loch Lomon. Escocia, Reino Unido.

Masiero, L. y Zoltan, J.

2013. Tourists intra-destination visits and transport model: A bivariate profit model. Annals of Tourism Research, vol. 43, pág. $529-446$.

McKercher, B.

2016. Towards a taxonomy of tourism products. Tourism Management, vol. 54, pág. 196 - 208. Organización de las Naciones Unidas

2010. International recommendations for tourism statistics 2008. Nueva York, Estados Unidos. Organización Mundial del Turismo

2007. A Practical Guide to Tourism Destination Management. World Tourism Organization Publications. 
Paulino Valldepérez, L. y Prats Planagumà, L.

2015. Zonificación turística en destinos rurales: Un enfoque basado en el consumo en Terres de l'Ebre.

Cuadernos de Estudios Empresariales. Norteamérica. Disponible en: <http://revistas.ucm.es/index. $\mathrm{php} / \mathrm{CESE} / \mathrm{article} / \mathrm{view} / 47663 / 44642>$

Renenger, A.

2002. Satellite Tracking and the Right to Privacy. Hastings Law Journal, vol. 53, pág. 549 - 565.

Shoval N. e Isaacson M.

2007. Tracking tourists in the digital age. Annals of Tourism Research, vol. 34, nº 1, pág. $141-159$.

Shoval N., McKercher B., Ng E. y Birenboim A.

2011. Hotel location and tourist activity in cities. Annals of Tourism Research, vol. 38, nº 4, pág. 1594 - 1612.

Smallwood C., Beckley L. y Moore S.

2012. An analysis of visitor movement patterns using travel networks in a large marine park, north-western Australia. Tourism Management, vol. 33, pág. 517 - 528.

Wall, G.

1997. Tourism Attractions: Points, Lines, and Areas. Annals of Tourism Research, vol. 24, pág. 240 - 243.

Xiuli, T., \& Zhong, Q.

2005. The Application of Extension Theory in Tourism Resources Development. Proceedings of 2005 International Conference on Management Science and Engineering, 1319-1325.

Zoltan J. y McKercher B.

2015. Analysing intra-destination movements and activity participation of tourists through destination card consumption. Tourism Geographies, vol. 17, nº 1, pág. 19 - 35. 